\title{
Performance of Water Pump on Distribution and Transmission Process using Variable Speed Drive
}

\author{
Dwi Oktavianto Wahyu Nugroho ${ }^{1}$, Totok Soehartanto ${ }^{1}$, Tahta Anugrah Wibowo ${ }^{1}$
}

\begin{abstract}
The Pump is the vital component in the transmission of water from one unit to another or the distribution water from booster unit to customer. Water pumping has become ineffective due to incorrect installation of the installed pump not in accordance with the pre-installed piping. Investing in network development in the coming year is sometimes one of the reasons why pumps are installed improperly. Thus, high pressure pumps are sometimes installed at lower pipeline pressure. This condition usually does not only double between the pressure in the pipe and pump. Classically, pump output lines are usually coupled with valves (usually butterfly or rotary valves) to provide conditions that correspond to the pump's datasheet. Meanwhile, the classical concept will decrease the lifetime of pump, so the Variable Speed Drive (VSD) becomes the solution. TawangSari, SiwalanPanji, and KedungUling units are picture how VSD can fix kind of problem that faced in classical system. Worst energy use and decreased performance in classical system cause by wrong installation and limitation of supply power are solved by adapting frequency produced by VSD as it needed.
\end{abstract}

Keywords — Pump, Installation, Variable Speed Drive, Energy, Performance

\section{INTRODUCTION}

$\mathbf{P}$ ump in water distribution company (in this case PDAM "Delta Tirta" Sidoarjo, Indonesia) is the heart of water process business. Without pumping process, raw water cannot be transmitted to the water treatment unit and the purified water cannot be distributed to the customer. The disturbance on water pump cause the effects of water treatment and distribution, vice versa the increasing of pump performance can cause the improvement of water treatment and distribution. Another case the selecting of pump and pipeline must also consider to the growth of customer on the next year (next 5 years minimum). The selection of pump and pipeline accordance with previous statement, cause pump with the higher pressure and pipeline with larger size are selected, as an impact the pump will not meet an ideal condition to pump a water. This paper discusses the differences between the classical system and the inverter system used in pump distribution by data collected from the PDAM Delta Delta unit that has been switched from the classic system to the Variable Speed Drive (VSD) system. The data used as a discussion is taken at the time of the system changes (2011 -2012) in order to get the right pattern of change between the classical system with inverter system.

In classical way the outlet pump line is coupled by an adjustable valve (V1) to solve that problem as seen on Figure 1, meanwhile check valve (V2) is used as protection of water hammer if pump shutoff or shutdown.

\footnotetext{
${ }^{1}$ Departement of Instrumentation Engineering, Faculty of Vocational Studies, Institut Teknologi Sepuluh Nopember, Surabaya, 60111, Indonesia. Oktaviantowndwi@gmail.com
}

The classical method can cause another problem if not came along with good installation, such as the impeller of pump will grind by the water if the valve installation too close to the pump; any damage on valve that make the valve cannot open as it should be, can cause the water trap between pump and valve which burn the pump motor and grind the impeller; etc. In pumping systems, opening / closing the discharge valve and starting / closing the pump can cause a sudden change in the speed of the water inside, and in turn a sharp change in water pressure. While the water velocity and pressure change, pump parameters, such as capacity, head, rotation, and torque, etc. also change instantly [1].

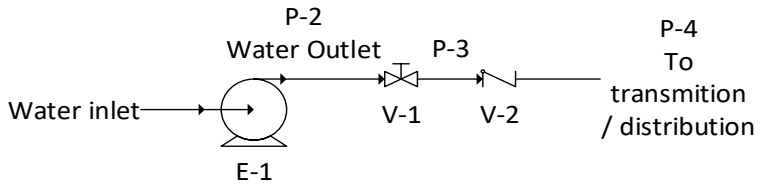

Figure 1. Classical pumping system adaptation

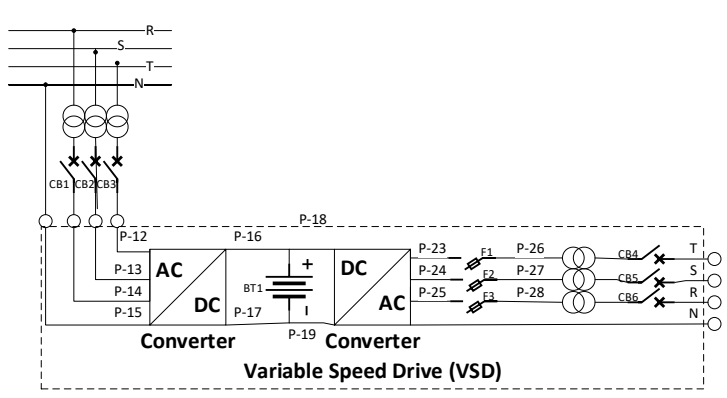

Figure 2. Variable Speed Drive as modern technique to control the motor pump 
A non-optimal of the pump performance become another effect beside the problem that cause by imperfect installation. This non-optimal performance is caused by the head pump that is not in line with the pipe network head. Sometimes to meet the head that required by a pump, the valve is closed more than a half of pipe size, which mean the pressure between impeller pump to valve increase (allows an increase of the friction force that can crushes the impeller). The air that trap after the pump shut off for a long time, and imbalance voltage are also kind of problem that make the pump could not use it optimal performance. A non-optimal performance can make the life time of the pump decrease, higher power consumption, the water that lift by the pump is fewer than expected, and increasing heat of pump motor. Thus the need of optimal performance of the pump become something important to reach an optimal water lifting and prolong the life time of the pump (at least like a pump data sheet). Impeller trimming sometimes selected to achieving the optimal performance of pump, but this strategy made the performance of the pump lower permanently.

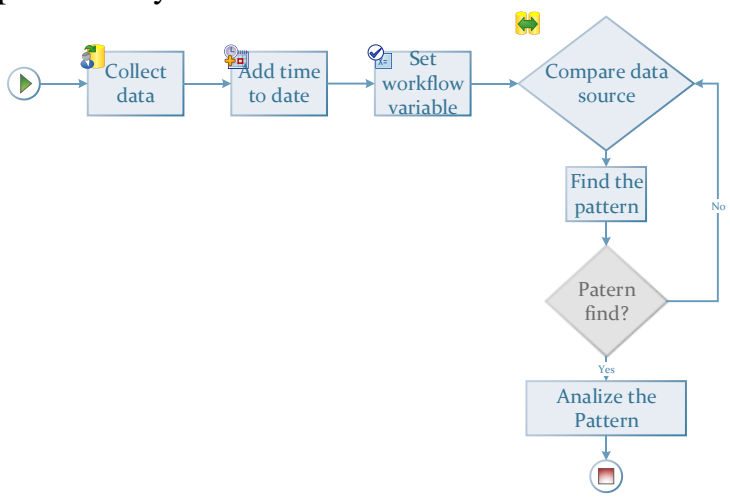

Figure 3. Flow Chart of work flow

Variable Speed Drive (VSD) or sometimes call as inverter become a modern technique to control and getting a performance variability of the pump. Generally, Variable Speed Drive collected three phase AC source (R, S, and T) into DC source and generated a new pure three phase AC source with adjustable frequency as seen on Figure 2. The benefit of adjustable frequency is an ability to control the rotation speed of motor pump thus the pump has variable output of water accordance to the output frequency of VSD.

The adaptation of VSD then applied to solve the pump installation problem (in this case applied in PDAM "Delta Tirta", Sidoarjo in booster unit Tawangsari, booster unit Kedunguling and Water Treatment Unit Siwalanpanji). Each unit in case applied have different problem to solve by using VSD as pump motor control. Each case that solved also based on each pump specification to reach the aims which discuss later.

\section{METHOD}

The method used here are based on three basic concepts such as, Knowing the pump characteristic that planted on the unit, develop the problem using problem identification then analyzing the solution that applied to the system. The analizing done by collected the data of used power and flow rate before system switch and after and compare it to knowing the impact of system change and its pattern. The method is described as flow chart on Figure 3.

Flow chart shown on Figure 3, started by collecting the data that needed. This colecting data aims to get the correct perception of system switch from classical to VSD / Inverter. An addition of time and date in the data collection was done to get the timeline of events that occurred precisely. Variable selection of bunch of data and event that collected become the next step was done, to get information from the event and the data that been collected. Power used and flow rate selected to be prior information that gain from data bunch. The infromation data of variable selected, then compared using exact timeline to know the connection between power used by system and water that produced by system. The timeline comparation purposed to know the pattern between data and event on each unit and time which give result how the problem and solution can meet. The timeline and the event that collected also played a role as the exact problem detection and to know the solution has had a great impact on the system or not.

\section{RESULTS AND DISCUSSION}

An initial survey of AHU fan loads can indicate that a number of motors are significantly under loaded, and thus operate in the efficiency range of $75-85 \%$. When the induction motor operates in the efficiency range of 75-85 $\%$, the power reduction achieved for each percentage point increase is around I kW / $100 \mathrm{hp}$ from the actual load [2], thus same as pumping system, to increasing performance of the pump can be done by fixing the power of pump motor. The Result and Discussion bellow were presented using the method explained before, which composed of Pump Characteristic, Problem Identification and Solution analyzing.

\section{A. Pump Characteristic}

Pump operating points depend on 3 aspects, including the pressure of the water remaining from the city pipeline, the consumption of water in the building and the characteristic curve of the pump, between each change in factor can cause a change in the operating point [3]. 


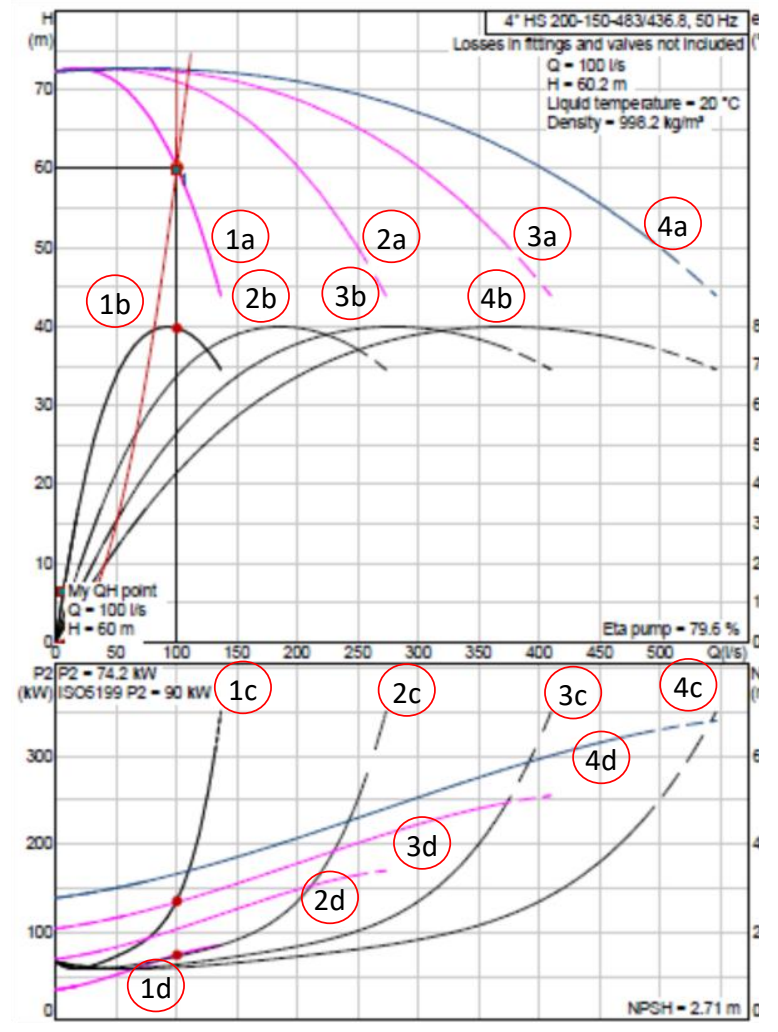

Figure 4. HS200-150-483 5/1-F-A-BBVP of pump datasheet which used in PDAM "Delta Tirta" Sidoarjo units [5]

The pump generally works according to its requirements, such as total head needed, NPSH, the desired flow rate, also power consumption and efficiency allowed. The requirements needed by a pump is described in its datasheet (in this case datasheet of pump type HS 200-150-483 5/1F-A-BBVP). HS type was selected because it was the pump that planted in the unit.

Figure 4 shows how the work of the pump. In upper curve shows the relation between Head requirement (on the left axis index), exit flow rate of the pump (on the horizontal axis index) and efficiency pump (on the right axis index) base on head requirement, exit flow rate, and frequency that applied to the motor. The "a" index in upper curve describe how the relation pattern of pump head vs debit of water, while the "b" index shows how the pump efficiency according to debit produced by the pump. The lower curve shows the relation of power of consequent used (on the left axis index), exit flow rate of the pump (on the horizontal axis index), and NPSH requirement for negative suction (on the right axis index). The $\mathrm{c}$ index was the curve between NPSH of the pump vs pump debit and the "d" index was the curve between the needed power by the pump vs pump debit. The number index inside the curve was typical pump used, "1" means single used, "2" mean two pump parallel used, "3" mean three pump parallel used, and " 4 " mean four pump parallel used.
The Box in Upper right index shows that the pump type HS 200-150-483/436.8 that coupled with 4 pole motor and the frequency that can be applied to the motor maximum 50Hz. The code type HS 200-150-483/436.8 means model type of pump is HS, pump inlet size is DN 200, pump outlet size is DN 150, and the size of impeller is $483 \mathrm{~mm}$ which trim to be 436.8 to reach condition $60 \mathrm{~m}$ of Total Head requirement and $100 \mathrm{l} / \mathrm{s}$ of flow rate. Which means the pump that already install on the unit has been trim before, so the curve between total head and flow rate become lower than supposed due to the head available on the pipeline. The other impact of the pump impeller trimmed is the performance of the pump permanently change. Pump efficiency can be maintained by creating pump motor speed variability due to a permanent change in the pump to get water pump variability, otherwise the motor pump will easily heat up and experience a power failure when changes in the pressure pipe occur. This variability is obtained by placing VSD as a control for the pump motor. Maximum performance can be obtained by replacing the $50 \mathrm{~Hz}$ motor with the $60 \mathrm{~Hz}$ motor, thus the pump will get a wider band of water flow rate than before. This wider band of water flow rate obtained due to the increasing of frequency will cause the increasing of the pump motor rotational speed. One must be reminded that the increase in speed must be limited, because if over speed occurs it will cause a slip rotation at the pump motor.

The characteristic curve of a centrifugal pump is given based on site measurements and mounting data by the least squares method.

$$
\begin{aligned}
& H=a_{0}-a_{2} Q^{2} \\
& \eta_{P}=b_{0}+b_{1} Q+b_{2} Q^{2}
\end{aligned}
$$

Where $H$ indicates the lifting of a centrifugal pump, $Q$ shows the centrifugal pump displacement, $\eta_{P}$ indicates the working efficiency of a centrifugal pump [3].

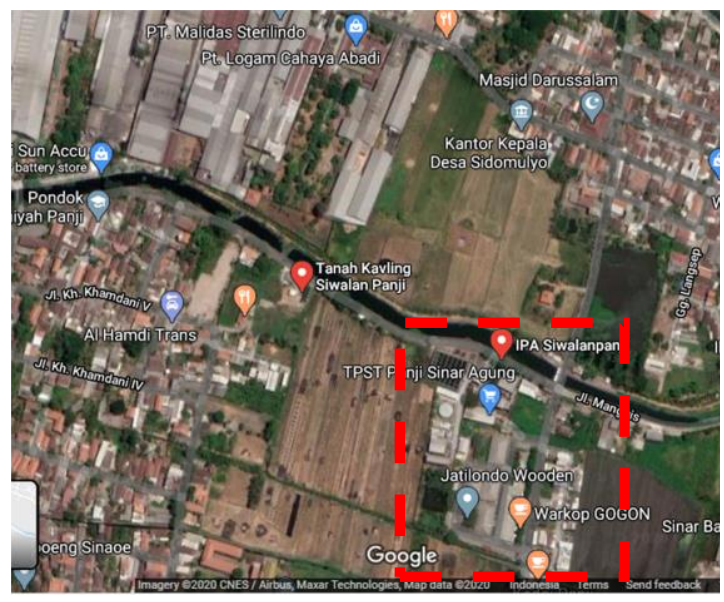

Figure 5. Location of Siwalanpanji unit [6] 


\section{B. Problem Identification}

Previous task explained about the pump condition which the next identification about the problem of each unit. The types of units of concern, such as the SiwalanPanji, KedungUling, and Tawangsari units will be explained below.

\section{B.1. SiwalanPanji Units.}

SiwalanPanji Unit was one of water treatment process from raw water till transmission to booster unit which takes raw water from Afvoer Buduran which shown in Figure 5. Figure 6 shows the conditions before (March 2011 - January 2012) and after (February 2012 - present) installation of VSD in the Siwalanpanji water treatment process (WTP) unit, the blue line informs the average flow rate of water pumped every month and the line yellow informs the average level of energy used by the pump to produce a flow of water in each month.

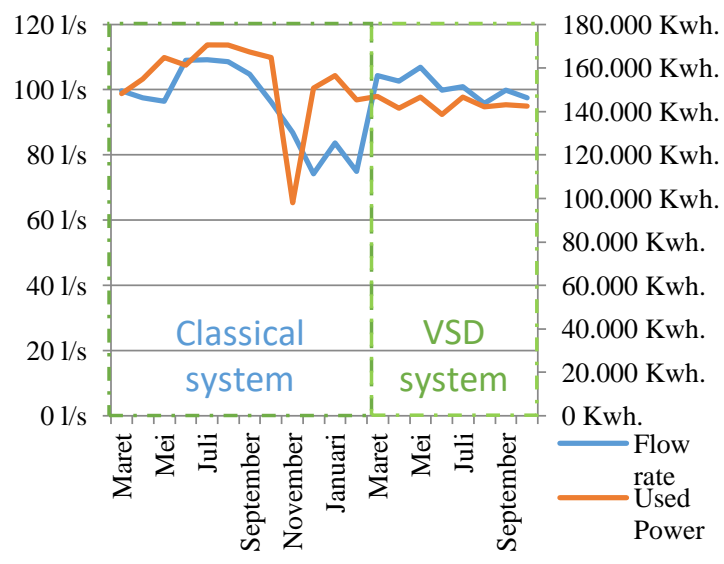

Figure 6. Power used and Flow rate in Water Treatment Siwalanpanji unit

Data collection every month is then compared between them to obtain trends in the production of water and energy flows used to produce them, so that they can obtain information about problems and how the impact of solutions implemented in the system unit. The Siwalanpanji WTP problem is that the use of power by the pump system is higher than the size of the water that can be raised and it can be seen that the pump system performance with the classical method decreases inversely with the increase in years. The high power used is caused by the selection of inappropriate pumps placed in the system, while the decrease in performance is caused by the growth of customers and impellers crushed by water trapped between the pump and valve (see Figure 1). The existing causes make the pump system unit unstable and easily cause power failures. Figure 6 also shows that in November to December the pump has worked beyond its capacity, so that power failure problems at the pump are more common.
Some solution has been applied to solve the problem before decision to placed VSD as control of the pump motor. Modification of the piping network in December to February to solve the power failure problem, came with other problems, the efficiency of the pump is worse than previously shown by the water discharge generated by the pump is lower but the energy used by the pump is very high, which means some energy is diverted to be heat, rather than being used to pump the water. In conclusion, SiwalanPanji faces the problems of increasing distribution pressure and distribution discharges in accordance with the Power limits applied in the Unit.

\section{B.2. KedungUling Units.}

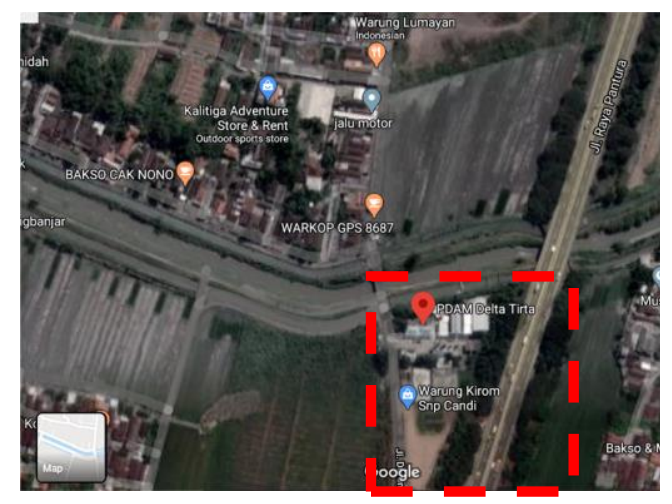

Figure 7. Location of KedungUling unit [7]

KedungUling is another Delta Tirta Sidoarjo PDAM Water Treatment Plant that takes raw water from the Brantas tributaries shown in Figure 7. KedungUling has different conditions from Siwalan Panji, in this case the transmission in the KedungUling unit uses two to three 50 1/s pumps to transmits the water where in the SiwalanPanji unit uses only one pump $100 \mathrm{l} / \mathrm{s}$ KedungUling and SiwalanPanji besides being used as water treatment, also aims to deliver processed water products to the booster and distribute them to customers. The purpose of transmission and distribution in the unit is the most important that gives effect to the power line rather than the water treatment process. Thus reason made the better perfomance on transmission and distribution more important and urgent.

Figure 8 provides information that prior to August 2011, pumping units had fluctuating conditions and never got the best conditions for transmitting water. August to November the pipeline modification solution did not seem effective to solve the problem, especially in October the power used was very high due to the decrease in network pressure. Network downturn in October was caused by network leakage which made the network drop exponentially and the pump system was easily shut down (power failure).

The situation shows that KedungUling units have different problems than SiwalanPanji units, KedungUling 
must face the pressure conditions are unstable network, which is not supported by the pump system under these conditions, and also means that KedungUling need better solutions to adapt to network conditions. Adaptability is needed by the KedungUling units to pump the water continuously despite network disruption.

\section{B.3. TawangSari Units.}

Tawangsari a third case in which the transitional system of the classical system to system inverter / VSD held. TawangSari takes raw water from the river "Pelayaran" which is a tributary of Berantas river. TawangSari problems and conditions also different from KedungUling and SiwalanPanji problems and conditions. TawangSari unit act only as transmission of water processed product. The Water transmission were support by seven parallel pump which some of those pump cannot reach it best condition. The maintain of the pump become important attention, because all the pump must be on same condition.

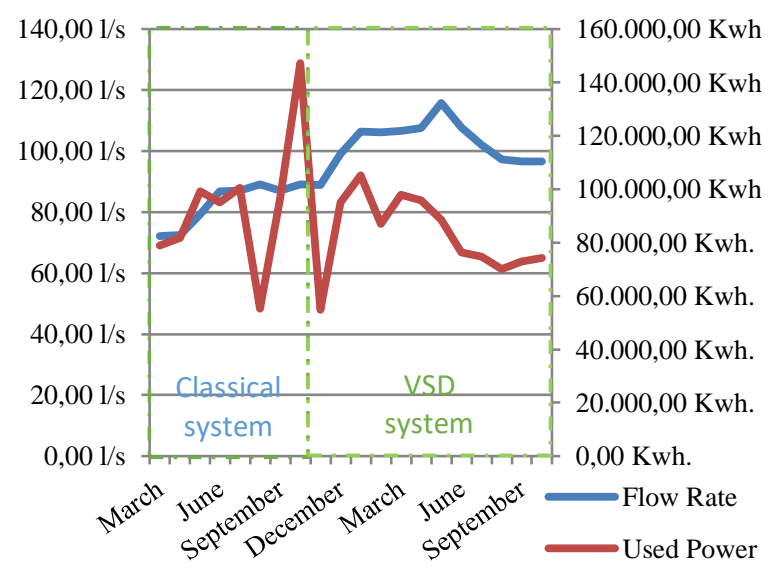

Figure 8. Power used and Flow rate in Water Treatment KedungUling unit

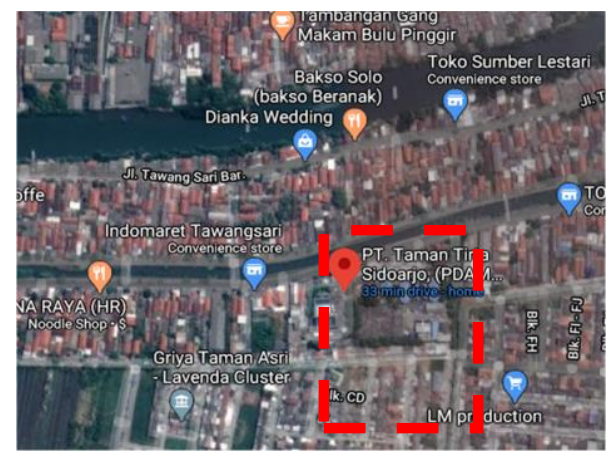

Figure 9. Location of TawangSari unit [8]
TABLE 1.

RELATION BETWEEN POLE AND MOTOR ROTATION IN $60 \mathrm{~Hz}$ FREQUENCY

\begin{tabular}{cc}
\hline Number Pole & Motor RPM \\
\hline 2 & 3600 \\
4 & 1800 \\
6 & 1200 \\
8 & 900 \\
10 & 720 \\
12 & 600 \\
\hline
\end{tabular}

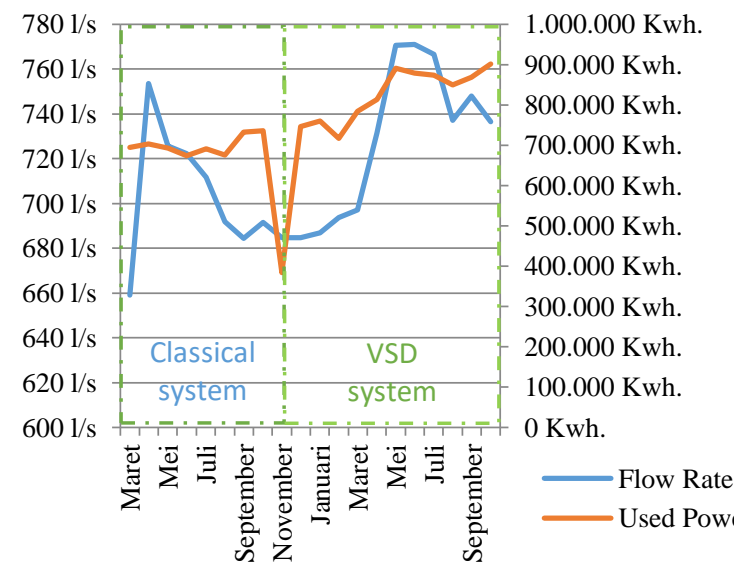

Figure 10. Power used and Flow rate in TawangSari unit

The dangerous problem if one of the pump not in same condition was the pump with weaker condition will be crush by the contra water flow produced by the stronger pump. The decrease performance of pump system become the time bomb if one of the pump having trouble.

Tawangsari was the main support of water distribution in Sidoarjo. Tawangsari unit supply the most water than the other unit. The problem of Tawangsari unit will cause great impact for water supply in Sidoarjo. Performance improvement of pump work become main concern because those reason beside the time bomb of decreasing performance.

Figure 10 gives information on May till November all the pump has decrease performances, the water transmits by the pump become fewer while energy that being used higher. This situation is caused by contra flow from water transmission which brakes the flow of pumped water. The crushed impeller and easily having power failure cannot be avoided because this situation which shown on November. Figure 10 shows that TawangSari faces an imbalance in parallel pump work so that the pump does not work optimally. 


\section{VSD Solution Analyzing}

The speed of synchronous AC motor is determined by the frequency that used and the number of pole which relation can be seen on Table 1. VSD main idea is modify the rotation of pump motor by changing the frequency that stimulated to the pump motor. This chapter discuss about the impact of using VSD / Inverter as solution to solve the problem faces by each unit. The problem of each unit resumed in Table 2. then used as the foundation how if the inverter / VSD replace the classical system. Figure 6 after March, SiwalanPanji unit was switch from classical into VSD system. After March showed that the problem was corrected, the water transmitted increased while the energy used was reduced. The changing pattern of water transmission now is in line with the changing pattern of energy used.

TABLE 2.

PROBLEM THAT FACED BY SIWALANPANJI UNITS, KEDUNGULING UNITS AND TAWANGSARI UNITS

\begin{tabular}{|c|c|c|}
\hline Number & Units & Problems \\
\hline 1 & SiwalanPanji & $\begin{array}{l}\text { Increasing distribution } \\
\text { pressure and distribution } \\
\text { discharges in accordance } \\
\text { with the Power limits } \\
\text { applied in the Unit }\end{array}$ \\
\hline 2 & KedungUling & Unstable network pressure \\
\hline 3 & TawangSari & $\begin{array}{l}\text { An imbalance in parallel } \\
\text { pump work }\end{array}$ \\
\hline
\end{tabular}

Figure 8, after November, KedungUling unit transforms the system from classical system being VSD system. Fluctuating water transmission can be seen from the unsteady of flow rate water transmission. The comparison between flow rate and power used gave the in line pattern, with the increasing flow rate and decreasing power used become better than before transformation.

Tawangsari underwent two stages of change, the first stage being held in January where half of the pump system was supported by VSD while the rest were still using the classic system. The first phase has an impact on increasing water transmission but the energy used by the system is still higher as shown on Figure 10. The second phase was held in April, where all pumps powered by VSD. The second stage results in higher water transmission results with lower power used. The situation in stage two is still of concern in monitoring the equilibrium performance of the seven pumps installed in parallel. The energy become worse than supposed, as seen on August (Figure 10), if the equilibrium did not reached, despite the flow rate of water transmission can be hold on the best condition.

\section{CONCLUSION}

VSD or sometimes called as inverter, become best solution in motor driving. The flexibility of its frequency that produced made VSD can control the rotation of motor as is needed. VSD as pump control can be became an alternative to solve many kind problem of classical pump system. The wide range of frequency of VSD must to be attention before used. The key point to use the VSD as pump control is knowing the device that been planted, knowing the problem, then used in problem area, if not it become useless device. SiwalanPanji units, KedungUling units and TawangSari units are the prove that VSD with correct setting (must accordance with the problem of the system) can be the solution of classical pump problem.

\section{REFERENCES}

[1] M. Zhu, X. Zhang, Y. Zhang and T. Wang, "Study on water hammer prevention in pumping water supply systems by multivalves," presented at the Int. Conf. on Hybrid Information Technology, Cheju Island, Korea, 2006.

[2] W. L. Stebbins, "A user's perspective on the application of adjustable speed drives and microprocessor control for hvac savings," presented at the IEEE Annual Textile Industry Technical Conference, Greenville, SC, USA, 1988.

[3] J. Zhijun and H. Yangyang, "Research of pump-selection in pressure-superposed water supply," presented at the IEEE Int. Conf. on Intelligent Computing and Intelligent Systems, Xiamen, China, 2010.

[4] G. Junzhong, Q. Yuansheng, X. Yafen and L. Yang, "Operation parameters optimization of centrifugal pumps in multi-sources water injection system," presented at the International Technology and Innovation Conference Hangzhou, China, 2006.

[5] Grundfoss, "HS 200-150-483 5/1-F-A-BBVP," Grundfoss.

[6] Google, [Online]. Available: https://www.google.com/maps/place/IPA+Siwalanpanji/@ $7.4294806,112.7317153,694 \mathrm{~m} /$ data $=! 3 \mathrm{~m} 2 ! 1 \mathrm{e} 3 ! 4 \mathrm{~b} 1 ! 4 \mathrm{~m} 8 ! 1 \mathrm{~m} 2 ! 2$ m1!1sPDAM+siwalanpanji!3m4!1s0x2dd7e6a0ba68ccaf:0x8cf2f $076714480 \mathrm{~b} 2 ! 8 \mathrm{~m} 2 ! 3 \mathrm{~d}-7.4294859 ! 4 \mathrm{~d} 112.733904$. [Accessed 11 07 2020].

[7] Google, [Online]. Available: https://www.google.com/maps/place/PDAM+Delta+Tirta/@ $7.4735845,112.6867185,16.33 \mathrm{z} / \mathrm{data}=! 4 \mathrm{~m} 12 ! 1 \mathrm{~m} 6 ! 3 \mathrm{~m} 5 ! 1 \mathrm{~s} 0 \times 2 \mathrm{dd}$ 7e14a69371adf:0xec8d5d0f1f59d285!2sPDAM+Delta+Tirta+Ka bupaten+Sidoarjo! $8 \mathrm{~m} 2$ ! $3 \mathrm{~d}-$

7.4507982!4d112.7132805!3m4!1s0x0:0xa584b65bd7a2666c!8 m2!3d-7.4742126. [Accessed 1207 2020].

[8] Google, [Online]. Available: https://www.google.com/maps/place/PT.+Taman+Tirta+Sidoarjo ,+(PDAM+Tawangsari)/@ -

7.3298157,112.705138,13z/data=!4m5!3m4!1s0x0:0xd67f3558e b6270ad!8m2!3d-7.3528053!4d112.67591. [Accessed $14 \quad 07$ 2020]. 